\title{
Activation of LVGCCs and CB1 receptors required for destabilization of reactivated contextual fear memories
}

\author{
Akinobu Suzuki, ${ }^{1,2}$ Takuya Mukawa, ${ }^{1}$ Akinori Tsukagoshi, ${ }^{1}$ Paul W. Frankland, ${ }^{3}$ \\ and Satoshi Kida ${ }^{1,2,4}$ \\ ${ }^{1}$ Department of Bioscience, Faculty of Applied Bioscience, Tokyo University of Agriculture, 1-1-1 Sakuragaoka, Setagaya-ku, \\ Tokyo 156-8502, Japan; ${ }^{2}$ Core Research for Evolutional Science and Technology, Japan Science and Technology Agency, \\ Saitama 332-0012, Japan; ${ }^{3}$ Program in Neurosciences and Mental Health, Hospital for Sick Children Research Institute, \\ Toronto, Ontario, Canada M5G1X8
}

Previous studies have shown that inhibiting protein synthesis shortly after reactivation impairs the subsequent expression of a previously consolidated fear memory. This has suggested that reactivation returns a memory to a labile state and that protein synthesis is required for the subsequent restabilization of memory. While the molecular mechanisms underlying the restabilization of reactivated memories are being uncovered, those underlying the initial destabilization are not known at all. Using a contextual fear conditioning paradigm in mice, here we show that LVGCCS or CBI receptors in hippocampus are required for the initial destabilization of reactivated memory. Either pharmacological blockade of hippocampal protein synthesis or genetic disruption of CREB-dependent transcription disrupts memory restabilization following reactivation. However, these effects were completely blocked when mice were treated with inhibitors of either LVGCCs or CBI receptors, indicating that LVGCCs or CBI receptors are required for the initial destabilization of reactivated memory. In control experiments, we show that blockade of LVGCCs or CBI receptors does not interfere with the ability of ANI to block protein synthesis, or with the ability of ANI to impair initial consolidation. These experiments begin to reveal mechanisms underlying the destabilization of previously consolidated memories following reactivation and indicate the importance of activation of LVGCCs and $\mathrm{CB1}$ in this process.

To generate long-term (stable) memory, short-term (labile) memory undergoes a gene expression-dependent stabilization process known as memory consolidation (Flexner et al. 1965; Davis and Squire 1984; McGaugh 2000). Although it was previously thought that this consolidation occurs just once, there is growing evidence that memory retrieval is a dynamic process that either reinforces or alters memory (Misanin et al. 1968; Schneider and Sherman 1968; Lewis 1979; Mactutus et al. 1979; Przybyslawski and Sara 1997; Nader et al. 2000; Sara 2000; Tronel et al. 2005; Tronson et al. 2006). For example, in fear conditioning paradigms, inhibition of protein synthesis before or immediately following brief re-exposure to the conditioning stimulus (CS) disrupts the subsequent memory expression (Abel et al. 1997; Kida et al. 2002; Suzuki et al. 2004). This has suggested that following reactivation, a fear memory is briefly transformed to a labile state and then restabilized through a gene expressiondependent reconsolidation process (Nader et al. 2000; Taubenfeld et al. 2001; Debiec et al. 2002; Kida et al. 2002). Recent studies have begun to identify the molecular mechanisms underlying the restabilization of reactivated memory (Taubenfeld et al. 2001; Kida et al. 2002; Lee et al. 2004; Duvarci et al. 2005; Miller and Marshall 2005; Tronson et al. 2006). However, those underlying the initial destabilization remain poorly understood (Alberini et al. 2006; but see Ben Mamou et al. 2006).

Two potential molecular substrates for destabilization have been identified in studies examining extinction of contextual fear memory. More prolonged re-exposure to the CS (in the ab-

${ }^{4}$ Corresponding author.

E-mail kida@nodai.ac.jp; fax 81-3-54772317.

Article is online at http://www.learnmem.org/cgi/doi/10.1101//m.888808. sence of the US) leads to extinction of fear memory (Pavlov 1927; Rescorla 2001; Myers and Davis 2002). Since extinction involves the formation of a new CS-no US inhibitory memory, it is not unexpected that blockade of protein synthesis prior to the extended re-exposure blocks the development of extinction (Berman and Dudai 2001; Vianna et al. 2001). However, less expected is that this blockade of protein synthesis does not interfere with the stability of the original memory trace (Eisenberg et al. 2003; Pedreira and Maldonado 2003; Suzuki et al. 2004; but see Duvarci et al. 2006). This suggests that at least some of the processes engaged during extinction (such as activation of L-type voltagegated calcium channels [LVGCCs] and cannabinoid receptor 1 [CB1], both of which are required for memory extinction) (Cain et al. 2002; Marsicano et al. 2002; Suzuki et al. 2004) may additionally regulate the stability of the original memory trace. We explored the possibility that activation of LVGCCs and CB1 receptors are key steps in destabilization of reactivated memories. We found that blockade of LVGCCs and CB1 receptors protects memories from the amnestic effects of either blocking protein synthesis or disrupting CREB function during fear memory reactivation.

\section{Results}

CBI and LVGCCs are required for memory extinction Previously we examined the relationship between re-exposure duration and stability of contextual fear memory in mice (Suzuki et al. 2004). We found that when mice were briefly re-exposed (3 min) to the conditioning chamber, systemic administration of ANI blocked subsequent expression of that memory. In contrast, longer-duration re-exposures (30 min) led to extinction of con- 


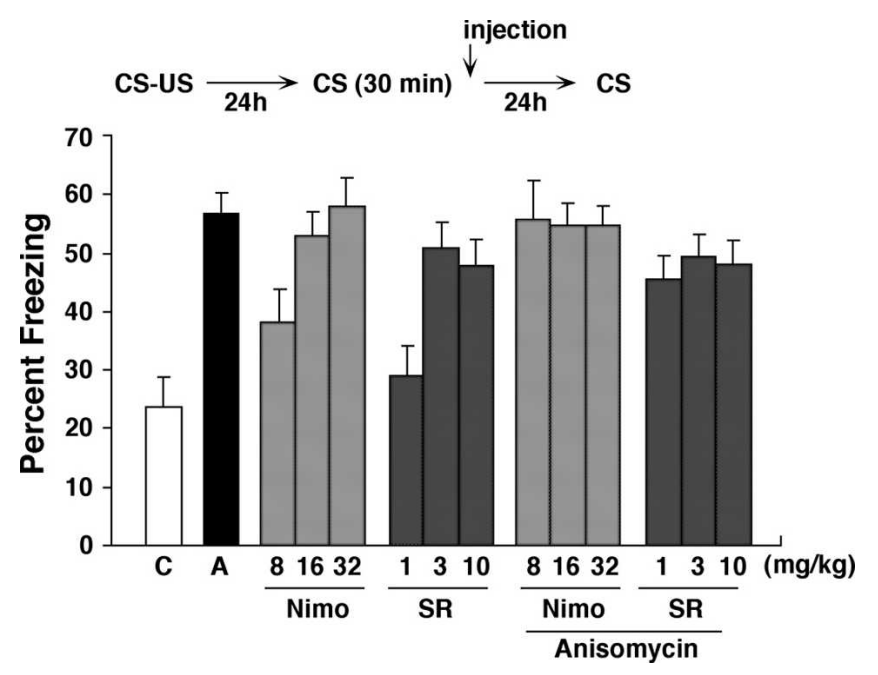

Figure 1. Effects of $A N I$ and $C B 1$ and LVGCCs antagonists on memory extinction. Experimental design used with data presented below. Mice were administered these drugs immediately after $30 \mathrm{~min}$ of re-exposure ( $n=12$ for all groups). (C) Control; (A) anisomycin; (Nimo) nimodipine; (SR) SR141716A.

textual fear memory, and extinction was blocked by administration of ANI, or pharmacological blockade of LVGCCs or CB1 receptors. In the first experiment, we verified that pharmacological blockade of either protein synthesis, LVGCCs, or CB1 block extinction of contextual fear conditioning groups (Fig. 1). In our previous studies, these treatments were administered $30 \mathrm{~min}$ prior to re-exposure (Suzuki et al. 2004). Here we examined the effects of these same treatments given immediately following re-exposure. The advantage of this design is that it allows us to eliminate the possibility that injections of these drugs affect the fear memory retrieval and within-session extinction. During training, mice received a single footshock $(0.4 \mathrm{~mA})$. Twenty-four hours following training, mice were placed back into the context for $30 \mathrm{~min}$. During this re-exposure, overall freezing levels did not differ across groups (data not shown) (all $P^{\prime} \mathrm{s}>0.05$ ), but did decrease over time, indicating that within-session extinction occurred $\left(F_{(9,1188)}=196.5, P<0.001\right)$. One day later, mice were placed back in the same context for $5 \mathrm{~min}$. Consistent with our previous experiments, pharmacological inhibition of protein synthesis blocked long-term extinction of contextual fear conditioning $\left(F_{(1,22)}=28.26, P<0.001\right)$ : Mice treated with ANI $(150$ $\mathrm{mg} / \mathrm{kg}$ ) showed higher levels of freezing compared to vehicletreated mice in this test $1 \mathrm{~d}$ following the extinction session. Next we examined whether coadministration of either nimodipine (LVGCCs antagonist; 8-32 mg/kg) or SR141716A (CB1 antagonist; $1-10 \mathrm{mg} / \mathrm{kg}$ ) would interfere with this ANI-induced blockade of extinction. We found that groups of mice coadministered Nim/ANI or SR/ANI showed similarly high levels of contextual fear memory, indicating that these treatments did not interfere with the ability of ANI to block extinction. In contrast, nimodipine and SR141716A blocked extinction in a dose-dependent manner, as previously observed (Suzuki et al. 2004). A factorial ANOVA with Drug1 (Vehicle VS ANI), Drug 2 (nimodipine VS SR141716A), and dose (low, middle, high) confirmed these observations: Most critically, there was no significant Drug1 $\times$ Drug2 interaction $\left(F_{(1,132)}=0.003, P=0.95\right)$, indicating similar levels of freezing in nimodipine- and SR141716A-treated groups regardless of whether they were coadministered ANI. There were main effects of Drug2 $\left(F_{(1,132)}=7.55, P<0.01\right)$, reflecting generally higher levels of freezing in mice treated with Nim, and Dose $\left(F_{(2,132)}=6.31, P<0.01\right)$, reflecting generally higher levels of freezing in mice treated with higher doses of Nim or SR. In addition, there was a significant Drug $1 \times$ Dose interaction $\left(F_{(2,132)}=5.03, P<0.01\right)$, indicating that dose-dependent effects were only observed in Vehicle-treated groups (Fig. 1). Together these data confirm previous experiments (Suzuki et al. 2004) and show that extinction depends on activation of LVGCCs, CB1 receptors, and protein synthesis.

\section{CBI and LVGCCs are required for destabilization of reactivated memory}

Blocking protein synthesis either before or after brief re-exposure to context leads to a disruption of subsequent expression of contextual fear memory. This indicates that new protein synthesis is required for the restabilization of contextual fear memories after memory reactivation (Debiec et al. 2002; Kida et al. 2002; Suzuki et al. 2004). We next tested whether the blockade of LVGCCs and CB1 receptors would block the amnestic effects of ANI on a reactivated memory (Fig. 2). During training, mice received a single footshock $(0.4 \mathrm{~mA})$. Twenty-four hours following training mice were placed back into the context for $3 \mathrm{~min}$. During this reexposure, overall freezing levels did not differ across groups (data not shown) (all $P$ 's $>0.05$ ). As we have previously shown, administration of ANI immediately following this re-exposure impaired the expression of contextual fear memory tested $24 \mathrm{~h}$ later $\left(F_{(1,22)}=25.50, P<0.001\right)$. In this test, ANI-treated mice exhibited significantly lower freezing levels compared to vehicletreated mice. Next we examined whether coadministration of either nimodipine $(8-32 \mathrm{mg} / \mathrm{kg})$ or SR141716A $(1-10 \mathrm{mg} / \mathrm{kg})$ would block the amnestic effects of ANI on memory expression. Notably, the disruption of reactivated fear memory by ANI was reversed by coadministration of either nimodipine or SR141716A in a dose-dependent manner: Mice that were coadministered Nim/ANI or SR/ANI exhibited similar levels of contextual fear memory compared to mice treated with either nimodipine or SR141716A alone. A factorial ANOVA with Drug1 (Vehicle VS ANI), Drug 2 (nimodipine VS SR141716A), and Dose (low, middle, high) confirmed these observations. Most critically, there was no significant Drug $1 \times$ Drug 2 interaction $\left(F_{(1,132)}=0.20, P=0.65\right)$, indicating similar levels of freezing in nimodipine and SR141716A regardless of whether they were

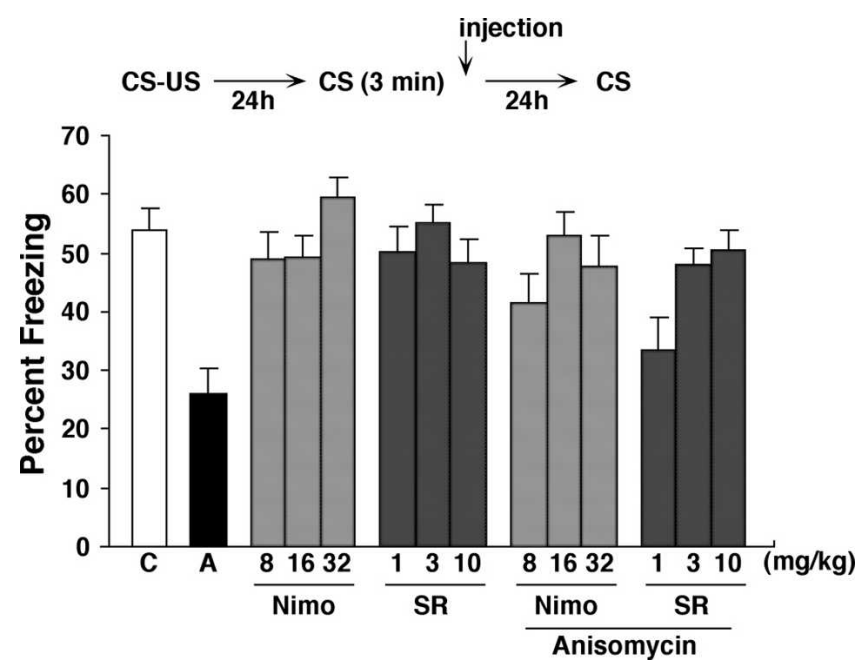

Figure 2. Effects of $A N I$ and $C B 1$ and LVGCCs antagonists on memory reconsolidation. Experimental design used with data presented below. Mice were administered these drugs immediately after $3 \mathrm{~min}$ of reexposure ( $n=12$ for all groups). (C) Control; (A) anisomycin; (Nimo) nimodipine; (SR) SR141716A. 


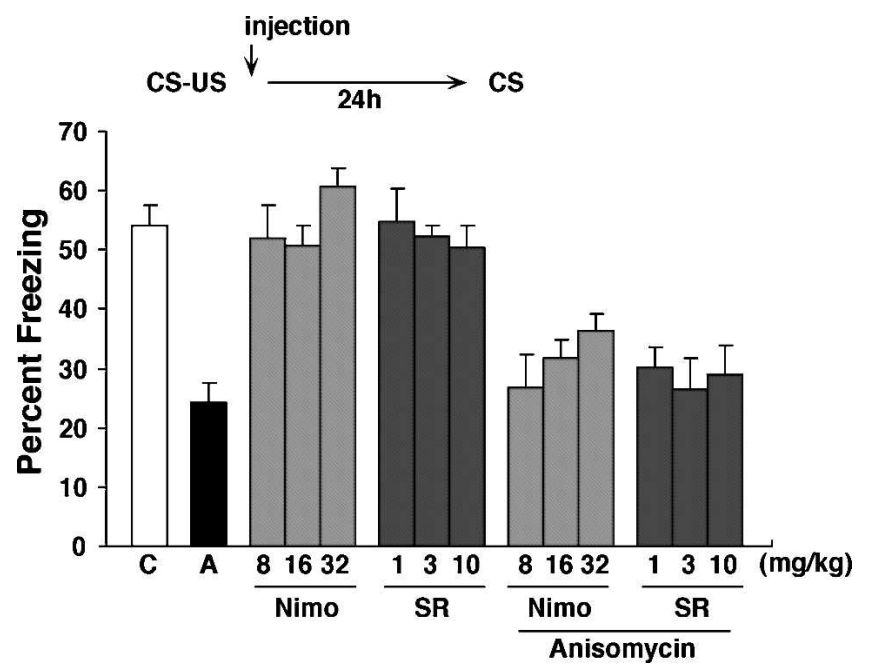

Figure 3. Effects of CB1 and LVGCCs antagonists on memory consolidation. Experimental design used with data presented below. Mice were administered these drugs immediately after training $(n=10$ for all groups). (C) Control; (A) anisomycin; (Nimo) nimodipine; (SR) SR141716A.

coadministered ANI. There were main effects of Drug1 $\left(F_{(1,132)}=6.70, P<0.05\right)$, reflecting modest reductions in freezing in some groups of mice treated with ANI, and Dose $\left(F_{(2,132)}=4.91, P<0.001\right)$, indicating that lower doses of nimodipine and SR141716A were typically associated with lower levels of freezing (Fig. 2). Consistent with previous studies, these results first indicate that new proteins are required for the restabilization of memories following retrieval. Blocking protein synthesis immediately following retrieval disrupted expression of contextual fear memory tested $24 \mathrm{~h}$ later. Perhaps most strikingly, these effects were completely prevented by blocking LVGCCs and CB1 receptors. This suggests that activation of LVGCCs and CB1 receptors may be necessary for destabilization of contextual fear memory following retrieval.

\section{Blockade of CBI and LVGCCs does not interfere} with the amnestic effects of $\mathrm{ANI}$ on initial consolidation To explore this phenomenon more comprehensively, we next examined the effects of administration of pharmacological blockade of protein synthesis, LVGCCs, or CB1 on the initial consolidation of a contextual fear memory (Fig. 3). If nimodipine and SR141716A prevent the destabilization of memories following retrieval, then we reasoned that these treatments should only be effective at blocking the effects of ANI following memory reactivation and not following initial learning. Accordingly, mice were trained with a single footshock $(0.4 \mathrm{~mA})$. As expected, mice receiving post-training injections of ANI exhibited significantly reduced levels of freezing when tested $24 \mathrm{~h}$ later $\left(F_{(1,22)}=31.56\right.$, $P<0.001)$. Consistent with previous experiments, these results indicate that de novo protein synthesis is essential for the formation of long-term contextual fear memories. To examine whether the amnestic effects of ANI would be blocked by pharmacological blockade of LVGCCs or CB1, mice were injected with different combinations of ANI, nimodipine, or SR141716A immediately following training. Mice that were coadministered Nim/ANI or SR/ANI exhibited reduced levels of contextual fear memory compared to mice treated with only either nimodipine or SR141716A alone. A factorial ANOVA with Drug1 (Vehicle VS ANI), Drug 2 (nimodipine VS SR141716A), and Dose (low, middle, high) confirmed these observations. There was only a main effect of Drug1 $\left(F_{(1,77)}=77.19, P<0.001\right)$, indicating reduced levels of freezing in mice treated with ANI (Fig. 3). No other main effects and interactions were significant. Therefore, these data reveal an important dissociation: Nimodipine and SR141716A block the amnestic effects of ANI only following memory reactivation and not during initial consolidation. Together they are consistent with a role for LVGCCs or CB1 receptors in memory destabilization following retrieval. Because the combined drug treatments were associated with reduced freezing levels, they further show that neither Nim/ANI nor SR/ANI induce nonspecific increases in anxiety and fear.

\section{Blockade of CB1 and LVGCCs does not interfere with the ability of ANI to block protein synthesis} Since coadministration of either nimodipine or SR141716A failed to prevent the memory consolidation impairment induced by ANI, these data additionally suggest that these drugs do not interfere with the ability of ANI to block protein synthesis. We next explored this issue in more detail by examining induction of the immediate early gene, $c$-fos, produced by the chemical convulsant pentylenetetrazol (PTZ) (Fig. 4). This approach has previously been used to examine Drug $\times$ Drug interactions since the PTZ-induced expression of Fos is strong (Frankland et al. 2006). Mice were pretreated with vehicle, nimodipine, or SR141716A. Thirty minutes following this pretreatment, mice received an in-

A

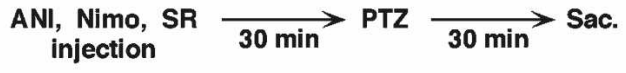
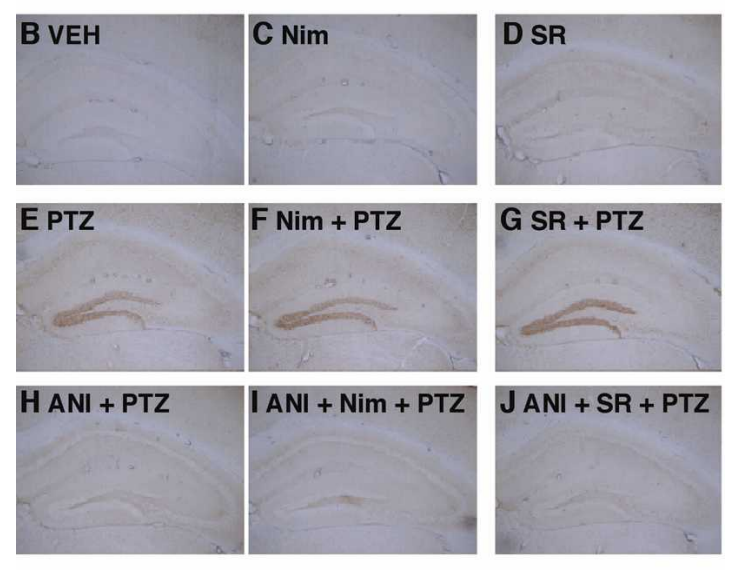

K

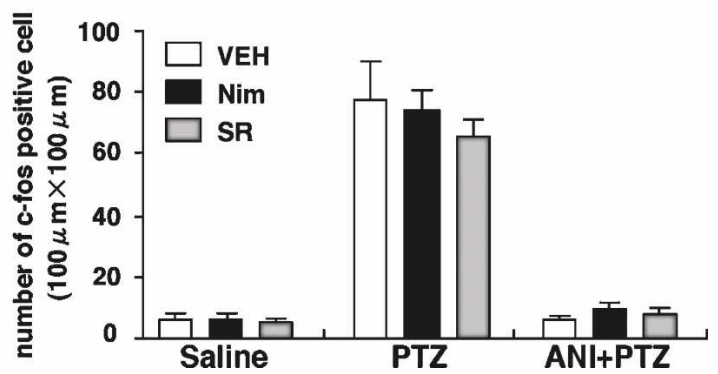

Figure 4. Effects of $C B 1$ and LVGCCs antagonists on the inhibition of the PTZ-induced c-fos protein expression by anisomycin. (A) Experimental design. (B-f) Representative hippocampal c-fos protein immunohistochemistry obtained from indicated mice. $(K)$ Quantitative analyses of cfos expression in dentate gyrus ( $n=4$ for all groups). (VEH) Vehicle; (Nim) nimodipine; (SR) SR141716A; (ANI) anisomycin. 
jection of saline, PTZ (50 mg/kg, i.p.) or a combined PTZ + ANI injection (Fig. 4A). This dose of PTZ produced clonic convulsions (i.e., sudden twitching of head or jerky movement of body) in the majority of mice. We found that PTZ induced Fos expression in the dentate gyrus, and that this effect was blocked by coadministration of ANI. Most importantly, the ability of ANI to block PTZ-induced Fos expression was not affected by pretreatment with either nimodipine or SR141716A (Fig. 4B-J). These observations were supported by a factorial ANOVA with Drug1 (Vehicle, PTZ VS PTZ/ANI) and Drug 2 (Vehicle, nimodipine VS SR141716A) as factors. This analysis revealed significant effects of Drug1 $\left(F_{(2,27)}=164.32, P<0.001\right)$, consistent with the elevated levels of Fos expression in the PTZ-treated mice. However, there were no significant effects of Drug $2\left(F_{(2,27)}=0.49, P=0.62\right)$ nor significant interaction between Drug1 and Drug2 $\left(F_{(4,27)}=0.54\right.$, $P=0.71)$. Post hoc Newman-Keuls test confirmed that robust Fos expression was observed in the dentate gyrus in PTZ-treated mice compared to saline-treated mice $(P<0.001)$, and levels were similar in mice pretreated with vehicle, nimodipine, or SR141716A $(P>0.05)$ (Fig. 4K). Together with the previous experiment, these data strongly suggest that neither nimodipine nor SR141716A interferes with the ability of ANI to block protein synthesis.

\section{Blockade of LVGCCs protects reactivated memories against the amnesic effects of inhibition of CREB activity}

We have previously shown that normal CREB function is required for the restabilization of contextual fear memory following reactivation (Kida et al. 2002). Therefore we next asked whether the effects of disrupting CREB function might be blocked by pharmacological blockade of LVGCCs (Fig. 5). To disrupt CREB function, we used transgenic mice that express an inducible $\mathrm{CREB}$ repressor $\left(\mathrm{CREB}^{\mathrm{IR}}\right)$ in forebrain, where a dominant-negative CREB protein is fused with the ligand-binding domain (LBD) of a mutant estrogen receptor (ER). Injection of tamoxifen (TAM), the artificial ligand for ER, into these transgenic mice inhibits CREB activity in forebrain. In these experiments, $\mathrm{CREB}^{\mathrm{IR}}$ and WT littermate controls were trained with a single footshock and re-exposed to the context for $3 \min 1 \mathrm{~d}$ later. Six hours prior to the re-exposure, mice received systemic injection of TAM or VEH. All groups showed comparable levels of

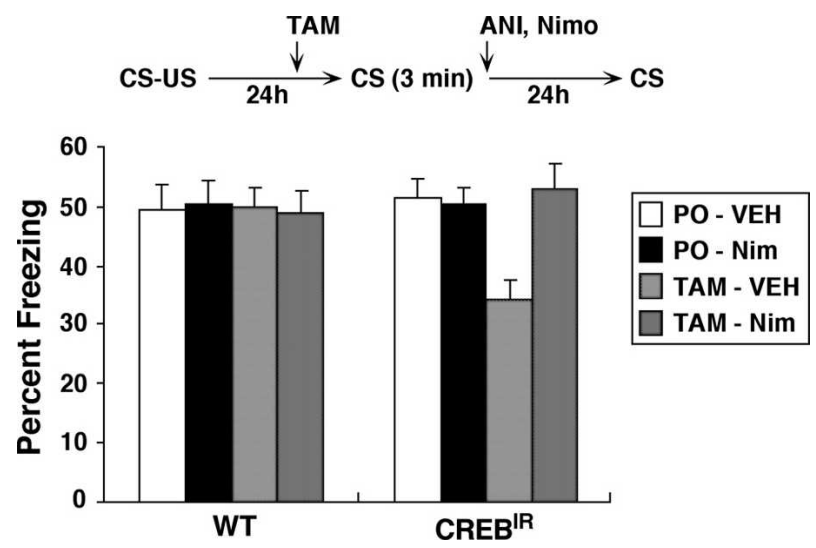

Figure 5. Effects of LVGCCs antagonists on disruption of reactivated memory by the inhibition of CREB activity. Experimental design used with data presented below. WT and CREB ${ }^{\mathrm{IR}}$ mice were administered TAM or Peanut Oil (PO) $6 \mathrm{~h}$ before re-exposure $(3 \mathrm{~min})$ and then administered nimodipine (Nim) or vehicle (VEH) immediately after re-exposure (WT/ PO/VEH, $n=15$; WT/PO/Nim, $n=17$; WT/TAM/VEH, $n=17$; WT/TAM/ Nim, $n=13 ; \mathrm{CREB}^{\mathrm{IR}} / \mathrm{PO} / \mathrm{VEH}, n=12, \mathrm{CREB}^{\mathrm{IR}} / \mathrm{PO} / \mathrm{Nim}, n=13 ; \mathrm{CREB}^{\mathrm{IR}} /$ $\mathrm{TAM} / \mathrm{VEH}, n=13, \mathrm{CREB}^{\mathrm{R}} / \mathrm{TAM} / \mathrm{Nim}, n=14$ ). freezing during the re-exposure (data not shown) (all $P^{\prime}$ s $>0.05$ ). When contextual fear memory was tested $24 \mathrm{~h}$ later, freezing levels were reduced in $\mathrm{CREB}^{\mathrm{IR}}$ treated with TAM. Importantly, these deficits were not due to injection of TAM alone, since freezing levels were normal in WT mice treated with TAM. Furthermore, these deficits were not due to expression of the CREB repressor alone. Freezing levels in the $\mathrm{CREB}^{\mathrm{IR}}$ treated with VEH were normal. Therefore, consistent with our previous study, these data indicate that normal CREB function is required for the restabilization of reactivated contextual fear memory. Most strikingly, these effects were completely blocked by treatment with nimodipine. $\mathrm{CREB}^{\mathrm{IR}}$ mice coinjected nimodipine with TAM showed comparable levels of freezing compared with other control groups, indicating that blocking LVGCCs prevented the disruption of contextual fear memory by inhibition of CREB activity during reactivation. Consistent with these observations, a factorial ANOVA revealed a significant three-way interaction between Genotype (WT VS CREB ${ }^{\mathrm{IR}}$ ), Drug1 (Vehicle VS TAM), and Drug 2 (Vehicle VS nimodipine): $\left(F_{(1,109)}=5.39, P<0.05\right)$. There were no other significant main effects or interactions, and post hoc Newman-Keuls tests confirmed that freezing levels were significantly reduced in $\mathrm{CREB}^{\mathrm{IR}}$ mice compared to all other groups (all; $P<0.05$ ) (Fig. 5). Together with our earlier experiments, these data indicate that LVGCCs play a role in memory destabilization following reactivation. Blockade of LVGCCs protect reactivated memories against the amnesic effects of protein synthesis inhibition and inhibition of CREB activity.

\section{Activation of CBI and LVGCCs in hippocampus is required for destabilization of reactivated memory}

Protein synthesis in the hippocampus is critical for the restabilization of contextual fear memory after reactivation (Debiec et al. 2002; Frankland et al. 2006). We therefore next tested whether activation of CB1 and LVGCCs in the hippocampus is required for the destabilization of reactivated contextual fear memory (Fig. 6). We therefore performed a similar experiment as in Figure 2 except that drugs were infused directly into the hippocampus, rather than delivered systemically. Mice received infusion of ANI with either CB1 blocker SR141716A or LVGCCs blocker Verapamil immediately after the 3-min re-exposure to the context (Fig. 6A). Consistent with previous findings (Debiec et al. 2002; Frankland et al. 2006), infusion of ANI into the hippocampus immediately following the re-exposure impaired the expression of contextual fear memory tested $24 \mathrm{~h}$ later $\left(F_{(1,56)}=11.324\right.$, $P<0.01)$. ANI-treated mice exhibited significantly lower freezing levels compared to vehicle-treated mice. These results indicate the essential roles of hippocampal protein synthesis in the restabilization of reactivated contextual fear memory, confirming previous findings. Next we examined whether coinfusion of either verapamil ( 0.5 or $2 \mu \mathrm{g}$ ) or SR141716A ( 2 or $4 \mu \mathrm{g}$ ) would block the amnestic effects of ANI in the hippocampus. Consistent with our experiments with systemic injections, the disruption of reactivated memory by ANI was reversed by coinfusion of either verapamil or SR141716A into the hippocampus in a dosedependent manner. Mice that were coinfused VER/ANI or SR/ANI into hippocampus exhibited similar levels of contextual fear memory compared to mice treated with either verapamil or SR141716A alone. A factorial ANOVA with Drug1 (Vehicle VS ANI), Drug 2 (verapamil VS SR141716A), and Dose (low, high) confirmed these observations: Most critically, there was no significant Drug1 $\times$ Drug2 interaction $\left(F_{(1,90)}=1.30, P=0.26\right)$, indicating similar levels of freezing in verapamil and SR141716A regardless of whether they were coadministered ANI (Fig. 6B). These results indicate that new hippocampal proteins are required for the restabilization of memories following retrieval. 
A

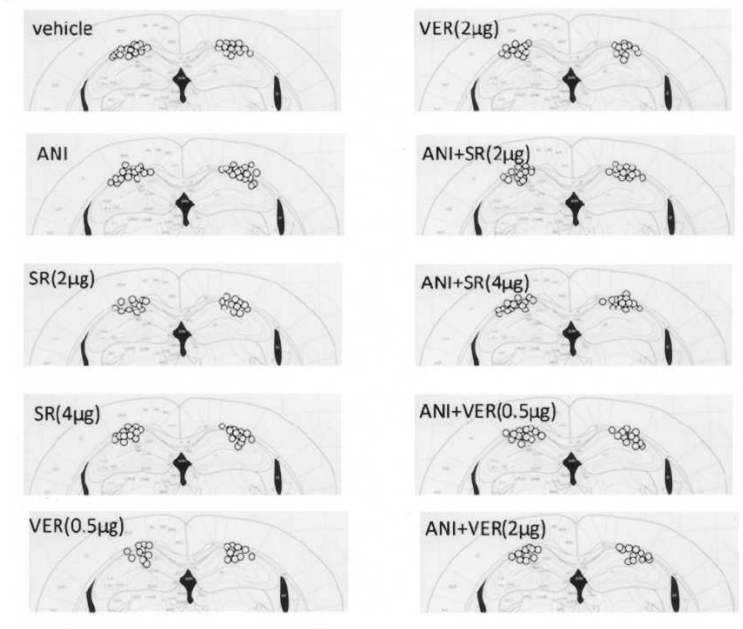

B
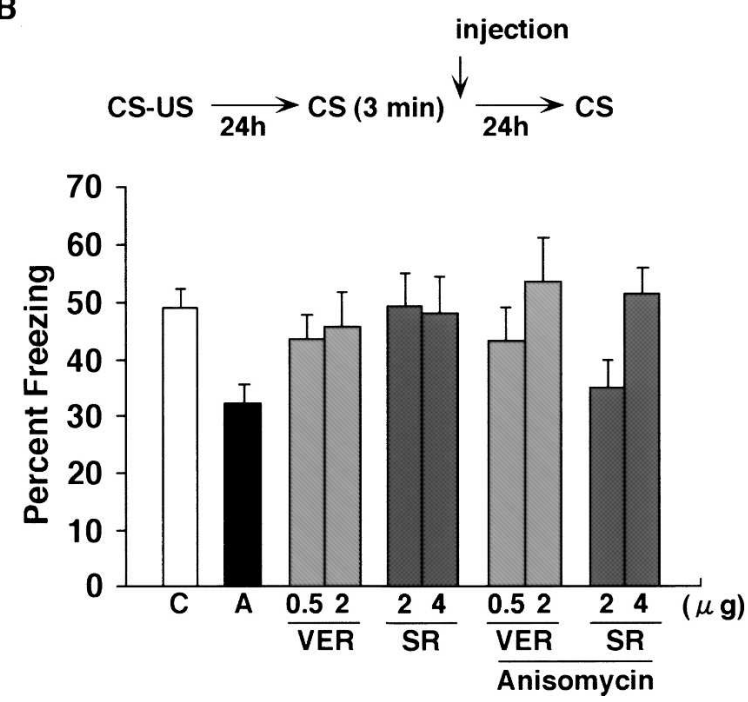

Figure 6. Effects of $\mathrm{ANI}$ and $\mathrm{CB} 1$ and LVGCCs antagonists on memory reconsolidation in hippocampus. (A) Cannula tip placements from mice infused with each drug. Coronal sections are adapted from Paxinos and Franklin (1997) (1.94 mm posterior to Bregma). (B) The experimental design used with the data presented below. Mice were administered these drugs into dorsal hippocampus immediately after $3 \mathrm{~min}$ of reexposure $(n=10-30)$. (C) Control; (A) anisomycin; (VER) verapamil; (SR) SR141716A.

More importantly, inhibitory effects of protein synthesis inhibition in hippocampus on restabilization of reactivated contextual fear memory were completely prevented by blocking LVGCCs and CB1 receptors. This suggests that the stability of reactivated memory (destabilization and restabilization) is regulated in the hippocampus and that activation of LVGCCs and CB1 receptors is required for the destabilization of reactivated contextual memory in hippocampus.

\section{Discussion}

Previous studies have shown that retrieval temporarily destabilizes fear memories, and that gene expression-dependent processes are required for subsequent restabilization (memory reconsolidation) (Nader et al. 2000; Taubenfeld et al. 2001; Debiec et al. 2002; Kida et al. 2002). While reconsolidation must encompass both a destabilization process and a restabilization process, molecular studies have focused almost exclusively on the latter (Taubenfeld et al. 2001; Kida et al. 2002; Lee et al. 2004; Duvarci et al. 2005; Miller and Marshall 2005; von Hertzen and Giese 2005; Tronson et al. 2006) with the exception of a recent report showing importance of glutamate receptors in destabilization of reactivated cued fear memory (Ben Mamou et al. 2006). These studies have shown that restabilization engages similar but distinct molecular process compared with initial consolidation. The studies presented here begin to unravel the molecular mechanisms underlying destabilization of reactivated memories. We show that activation of LVGCCs and CB1 receptors are required for the destabilization of fear memories following reactivation. Pharmacological blockade of these processes protected retrieved memories from the amnestic effects of anisomycin. Our findings indicate the existence of an active process inducing the destabilization of reactivated memory. This destabilization process might play a critical role in opening a window to update or strengthen original memory.

Memory reactivation initiates two competing processes: reconsolidation and extinction. Reconsolidation may serve to strengthen or modify the existing memory trace, whereas extinction involves the formation of an inhibitory memory that competes with the original fear memory. Because the temporal dynamics of these two processes differ, which comes to gain control over behavior depends, in part, on the duration of the retrieval episode (operationally the re-exposure in these studies): Reconsolidation is the dominant process following shorter duration re-exposures, whereas extinction is the dominant process following longer duration re-exposures (Debiec et al. 2002; Eisenberg et al. 2003; Nader 2003; Pedreira and Maldonado 2003; Suzuki et al. 2004). Previous studies have established that blocking protein synthesis during brief re-exposure disrupts the original fear memory, whereas blocking protein synthesis during longer reexposure blocks the formation of a new extinction memory (Eisenberg et al. 2003; Pedreira and Maldonado 2003; Suzuki et al. 2004). The requirement for protein synthesis in the formation of a new extinction memory is perhaps not surprising. However, the fact that protein synthesis inhibition selectively affects the formation of the extinction memory and leaves the original memory unaffected is surprising since both reconsolidation and extinction would be expected to be initiated under these conditions. These results suggest that the acquisition of a new extinction memory may transiently alter the stability of the original memory, raising the possibility that molecular processes engaged during extinction may also regulate the stability of the original trace, rendering it immune to amnestic challenges such as the application of protein synthesis inhibition (but see Duvarci et al. 2006).

Accordingly, our results indicate that pharmacological blockade of LVGCCs or CB1 receptors has two consequences on reactivated contextual fear memories. First, following longer reexposure to the context, pharmacological blockade of LVGCCs or CB1 blocks the formation of new extinction memory, as previously shown (Cain et al. 2002; Marsicano et al. 2002; Suzuki et al. 2004). Second, while pharmacological blockade of LVGCCs or CB1 did not affect reconsolidation of the original fear memory following shorter $(3 \mathrm{~min})$ context re-exposure, they protected these memories against the amnestic effects of anisomycin. We similarly showed that blocking LVGCCs also prevented the disruption of reactivated contextual fear memory by inhibition of CREB activity, indicating that these blockers inhibit the disruption of reactivated memory by two independent pathways; inhibition of protein synthesis and CREB activity. Together, our results support the idea that blocking molecular processes involved in fear extinction also regulates the stability of the original fear memory. These effects are not simply due to nimodipine or 
SR141716A interfering with the ability of anisomycin to block protein synthesis. In a control experiment, we showed that coadministration of these drugs does not block the ability of anisomycin to inhibit c-fos expression induced by the chemical convulsant PTZ. Perhaps most importantly, these effects were specific to reactivated memories. Pharmacological blockade of LVGCCs or CB1 receptors did not block the amnestic effects of anisomycin on initial learning. This dissociation confirms that these treatments do not interfere with the ability of anisomycin to block protein synthesis and that these treatments specifically regulate the stability of reactivated fear memories. These findings suggest that memory reactivation triggers the activation of LVGCCs and CB1 receptor, leading to destabilization and/or extinction of contextual fear memory. Further studies are required to examine the possibility that formation of extinction memory leads to the destabilization of reactivated contextual fear memory. In this case, the destabilized memory might undergo restabilization without new protein synthesis (such as the redistribution or relocalization of pre-existing proteins).

Previous studies have shown that the restabilization of reactivated contextual fear memory requires new protein synthesis in hippocampus (Debiec et al. 2002; Frankland et al. 2006). We replicated these effects, showing that blocking hippocampal protein synthesis following reactivation disrupts the subsequent expression of a contextual fear memory. Most strikingly, blockade of LVGCCs or CB1 function in hippocampus prevented this disruption of reactivated contextual fear memory by protein synthesis inhibition. This finding localizes the destabilization process to the hippocampus, indicating that following reactivation, both destabilization and restabilization engage hippocampaldependent processes. Similar to this, a recent study has shown that the amygdala critically regulates the destabilization and restabilization of reactivated cued fear memory (Ben Mamou et al. 2006). On the other hand, abundant evidence has identified critical roles for extra-hippocampal regions such as the PFC and amygdala in contextual fear memory extinction (Myers and Davis 2002; Quirk et al. 2006; Ji and Maren 2007). Our findings further suggest that CB1 and LVGCCs play distinct roles in different brain regions. In the hippocampus, they mediate destabilization of contextual fear memory following reactivation, whereas they mediate extinction in other brain regions (i.e., PFC and amygdala).

Our results suggest that the activation of CB1-dependent signaling plays a key role in destabilization of the reactivated fear memory. Once destabilized, that memory would require new gene expression for subsequent restabilization. Interestingly, some studies suggest that activation of CB1-dependent signaling may facilitate destabilization to a degree where restabilization is no longer possible. Infusion of CB1 agonists into the amygdala or insular cortex following memory retrieval of cued fear or conditioned taste aversion, respectively, leads to subsequent deficits in expression of that memory (Lin et al. 2006; Kobilo et al. 2007). These observations support our conclusion that CB1 plays a role in the regulation of memory stability following the retrieval, as well as memory extinction.

How do CB1 and LVGCCs cooperatively regulate memory processes such as extinction and the destabilization of reactivated memory? LVGCCs are known to be expressed in postsynapse of excitatory neurons in hippocampus and increase in post-synaptic $\mathrm{Ca}^{2+}$ concentration in response to depolarization. In contrast, endocannabinoids are released in response to the increase in post-synaptic $\mathrm{Ca}^{2+}$ concentration and then act as a retrograde signal activates to activate pre-synaptic CB1 receptors leading to decreased neurotransmitter release in pre-synapse. Therefore, it is possible that CB1 is activated via the activation of post-synaptic LVGCCs.
The studies presented here show that LVGCCs and CB1 play key roles in not only extinction but also destabilization of contextual fear memory. Understanding the circumstances under which maladaptive memories become plastic (and modifiable) is of clear clinical relevance. Since LVGCCs and CB1-dependent processes are both important in weakening fear memories (destabilization and extinction of fear memory), they might serve as useful therapeutic targets for the treatment of conditions such PTSD and phobias.

\section{Materials and Methods}

\section{Mice}

All experiments were conducted according to the Guide for the Care and Use of Laboratory Animals, Japan Neuroscience Society. Male C57BL/6N mice were obtained from Charles River (Yokohama, Japan). Transgenic mice expressing inducible CREB repressor (CREB ${ }^{\mathrm{IR}}$ mice) have been maintained since 1998 by backcrossing to C57BL/6 (more than F15 generations) (Kida et al. 2002). Mice were housed in cages of five or six, maintained on a 12-h light/dark cycle, and allowed free access to food and water. Mice were at least 8 wk of age when tested. Testing was carried out during the light phase of the cycle. All experiments were conducted blind to the treatment condition of the mouse.

\section{Surgery}

Surgeries were performed as described previously (Frankland et al. 2006). Under nembutal anesthesia and using standard stereotaxic procedures, stainless-steel guide cannula (22-gauge) were implanted into the dorsal hippocampus $(-1.8 \mathrm{~mm}, \pm 1.8 \mathrm{~mm}$, $-1.9 \mathrm{~mm}$ ). Mice were allowed to recover for at least $1 \mathrm{wk}$ following surgery. Following this, they were handled for three consecutive days prior to the commencement of contextual fear conditioning of the mice.

\section{Drugs}

Because the neural sites critically responsible for acquisition, extinction, and reconsolidation of fear memories may be different, we used systemic rather than intracranial injections of a protein synthesis inhibitor (anisomycin; ANI; Sigma), CB1 antagonist (SR141716A) (Rinaldi-Carmona, et al. 1994; Suzuki, et al. 2004), and L-type voltage-gated calcium channels (LVGCCs) antagonist (nimodipine; Sigma). ANI ( $150 \mathrm{mg} / \mathrm{kg}$, i.p.) was dissolved in PBS ( 1 drop of Tween 80 in $3 \mathrm{~mL}$ of $2.5 \%$ dimethylsulphoxide and $10 \%$ Cremophor in saline, $\mathrm{pH}$ adjusted to 7.0-7.4). At this dose, ANI inhibits $>90 \%$ of protein synthesis in the brain during the first $2 \mathrm{~h}$ following injection (Flood et al. 1973). SR141716A (1, 3, or $10 \mathrm{mg} / \mathrm{kg}$, i.p.) was dissolved in vehicle solution, containing 1 drop of Tween 80 in $3 \mathrm{~mL}$ of $2.5 \%$ dimethylsulphoxide and $10 \%$ Cremophor in saline. Nimodipine $(8,16$, or $32 \mathrm{mg} / \mathrm{kg}$, i.p.) was sonicated into $100 \%$ Cremophor EL (Sigma) and then diluted to make the final vehicle $10 \%$ Cremophor in solution (1 drop of Tween 80 in $3 \mathrm{~mL}$ of $2.5 \%$ dimethylsulphoxide). In these experiments, drug doses were determined according to previous reports showing effective doses for the blockade of long-term extinction (Cain et al. 2002; Marsicano et al. 2002; Suzuki et al. 2004).

For local infusion study, ANI $(125 \mu \mathrm{g} / \mu \mathrm{L}), \mathrm{SR} 141716 \mathrm{~A}$ (4 or $8 \mu \mathrm{g} / \mu \mathrm{L}$ ), and verapamil (LVGCCs antagonist; 1 or $4 \mu \mathrm{g} / \mu \mathrm{L}$; Sigma) was dissolved in vehicle solution, containing three drops of Tween 80 in $2.5 \mathrm{~mL}$ of $7.5 \%$ dimethylsulphoxide in artificial cerebrospinal fluid (ACSF) and adjusted to pH 7.4 with $\mathrm{NaOH}$.

For experiments using the CREB ${ }^{\mathrm{IR}}$ mice, 4-hydroxytamoxifen $(16 \mathrm{mg} / \mathrm{kg}$, i.p.; Sigma) was dissolved in $10 \mathrm{~mL}$ of peanut oil (Sigma) (Kida et al. 2002).

\section{Contextual fear conditioning}

Mice were trained and tested in conditioning chambers $(17.5 \times 17.5 \times 15 \mathrm{~cm})$ that had a stainless-steel grid floor through which footshocks could be delivered as previously described (Suzuki et al. 2004). Training consisted of placing the 
mice in the chamber and delivering an unsignaled footshock (2-sec duration, $0.4 \mathrm{~mA}$ ) $148 \mathrm{sec}$ later. Mice were returned to the homecage $30 \mathrm{sec}$ after the footshock.

To examine the effects of drugs on memory reconsolidation or extinction, mice were trained drug-free, and $24 \mathrm{~h}$ later placed back in the training context for 3 or 30 min during which freezing behavior was assessed (re-exposure) as the percentage of time mice spent freezing. Mice were treated with vehicle or drugs (ANI, SR, and nimodipine) immediately following removal from the context. Twenty-four hours later, mice were once again placed in the training context (5 min), and freezing behavior was assessed (Test) as the percentage of time mice spent freezing. For local infusion study, drugs (ANI, $62.5 \mathrm{mg}$; SR, 2-4 mg; VER, 0.5-2 $\mathrm{mg}$ ) were infused immediately following the re-exposure phase of the experiment. Infusions into dorsal hippocampus $(0.5 \mathrm{~mL})$ were made at a rate of $0.25 \mu \mathrm{L} / \mathrm{min}$. The injection cannula was left in place for $2 \mathrm{~min}$ following the infusion. This dose of locally infused ANI inhibits $>90 \%$ of protein synthesis for at least $4 \mathrm{~h}$ (Rosenblum et al. 1993). Locally infused VER and SR blocked the formation of cued fear memory (Bauer et al. 2002) or the extinction of conditioned taste aversion (Kobilo et al. 2007), respectively, in rat. In experiments using transgenic $\mathrm{CREB}^{\mathrm{IR}}$ repressor mice, TAM was administered $6 \mathrm{~h}$ before the re-exposure phase, and mice were tested $24 \mathrm{~h}$ later. Freezing behavior (defined as complete lack of movement, except for respiration) was automatically measured (O'Hara \& Co., Ltd.) (Anagnostaras et al. 2001).

In one series of experiments, we examined the effects of drug treatment on memory consolidation. In these experiments, mice were treated with saline or drug immediately after the training. Memory was assessed $24 \mathrm{~h}$ later as the percentage of time mice spent freezing.

\section{Immunocytochemistry}

To indirectly examine the impact of CB1 and LVGCCs blocker on protein synthesis inhibition by ANI, we examined the induction of the activity-regulated gene c-fos by the chemical convulsant pentylenetetrazol (PTZ; $50 \mathrm{mg} / \mathrm{kg}$, i.p.; Sigma). Separate groups of mice were pretreated with vehicle, nimodipine, or SR141716A, and 30 min later treated with VEH or PTZ. Another set of mice was pretreated with ANI in combination with either vehicle, nimodipine, or SR141716A, and then 30 min later treated PTZ. Thirty minutes later, all mice were perfused transcardially. Brains were subsequently prepared for immunocytochemistry using anti-c-Fos primary rabbit polyclonal antibody (Ab-5, 1:5000; Calbiochem), as previously described (Frankland et al. 2006). Staining was revealed using the streptavidin-biotin peroxidase method (SAB-PO kit; Nichirei Biosciences Inc.). Quantification of c-fos-positive cells in sections $(100 \mu \mathrm{m} \times 100 \mu \mathrm{m})$ of dentate gyrus (DG) was analyzed with Winroof Ver. 5.5 software (Mitani Corp.). The advantage of using PTZ in these experiments is that it induces high levels of c-Fos expression. This makes it easier to detect any reductions in c-Fos expression produced by pretreatment with ANI.

\section{Data analysis}

Data were analyzed with analysis of variance (ANOVA). A oneway or factorial ANOVA and post hoc Newman-Keuls comparisons were used to analyze the effects of drugs and genotypes. Analyses of planned comparisons were performed using a oneway ANOVA and post hoc Newman-Keuls comparisons. All values in the text and figure legends are means \pm SEM.

\section{Acknowledgments}

We thank Rui Costa for critical reading of the manuscript. S.K. was supported by Grant-in-Aids for Scientific Research, High Technology Research and Priority Areas-Molecular Brain Science (18022038) from the Ministry of Education, Science and Culture and Technology, Japan, Core Research for Evolutional Science and Technology, Japan, and the Research Grant for Nervous and Mental Disorders from the Ministry of Health, Labour, and Welfare, Japan.

\section{References}

Abel, T., Nguye, P.V., Barad, M., Deuel, T.A., Kandel, E.R., and Bourtchouladze, R. 1997. Genetic demonstration of a role for PKA in the late phase of LTP and in hippocampus-based long-term memory. Cell 88: 615-626.

Alberini, C.M., Milekic, M.H., and Tronel, S. 2006. Mechanisms of memory stabilization and de-stabilization. Cell. Mol. Life Sci. 63: 999-1008.

Anagnostaras, S.G., Gale, G.D., and Fanselow, M.S. 2001. Hippocampus and contextual fear conditioning: Recent controversies and advances. Hippocampus 11: 8-17.

Bauer, E.P., Schafe, G.E., and Ledoux, J.E. 2002. NMDA receptors and L-type voltage-gated calcium channels contribute to long-term potentiation and different components of fear memory formation in the lateral amygdala. J. Neurosci. 22: 5239-5249.

Ben Mamou, C., Gamache, K., and Nader, K. 2006. NMDA receptors are critical for unleashing consolidated auditory fear memories. Nat. Neurosci. 9: 1237-1239.

Berman, D.E. and Dudai, Y. 2001. Memory extinction, learning anew, and learning the new: Dissociation in the molecular machinery of learning in cortex. Science 291: 2417-2419.

Cain, C., Blouin, A., and Barad, M.G. 2002. L-type voltage-gated calcium channels are required for extinction, but not for acquisition or expression, of conditioned fear in mice. J. Neurosci. 22: 9113-9121.

Davis, H.P. and Squire, L.R. 1984. Protein synthesis and memory. Psychol. Bull. 96: 518-559.

Debiec, J., LeDoux, J.E., and Nader, K. 2002. Cellular and systems reconsolidation in the hippocampus. Neuron 36: 527-538.

Duvarci, S., Nader, K., and LeDoux, J.E. 2005. Activation of extracellular signal-regulated kinase- mitogen-activated protein kinase cascade in the amygdala is required for memory reconsolidation of auditory fear conditioning. Eur. J. Neurosci. 21: 283-289.

Duvarci, S., Mamou, C.B., and Nader, K. 2006. Extinction is not a sufficient condition to prevent fear memories from undergoing reconsolidation in the basolateral amygdala. Eur. J. Neurosci. 24: $249-260$.

Eisenberg, M., Kobilo, T., Berman, D.E., and Dudai, Y. 2003. Stability of retrieved memory: Inverse correlation with trace dominance. Science 301: $1102-1104$.

Flexner, L.B., Flexner, J.B., and Stellar, E. 1965. Memory and cerebral protein synthesis in mice as affected by graded amounts of puromycin. Exp. Neurol. 13: 264-272.

Flood, J.F., Rosenzweig, M.R., Bennett, E.L., and Orme, A.E. 1973. The influence of duration of protein synthesis inhibition on memory. Physiol. Behav. 10: 555-562.

Frankland, P.W., Ding, H.K., Takahashi, E., Suzuki, A., Kida, S., and Silva, A.J. 2006. Stability of recent and remote contextual fear memory. Learn. Mem. 13: 451-457.

Ji, J. and Maren, S. 2007. Hippocampal involvement in contextual modulation of fear extinction. Hippocampus 17: 749-758.

Kida, S., Josselyn, S.A., deOrtiz, S.P., Kogan, J.H., Chevere, I., Masushige, S., and Silva, A.J. 2002. CREB required for the stability of new and reactivated fear memories. Nat. Neurosci. 5: 348-355.

Kobilo, T., Hazvi, S., and Dudai, Y. 2007. Role of cortical cannabinoid CB1 receptor in conditioned taste aversion memory. Eur. J. Neurosci. 25: 3417-3421.

Lee, J.L., Everitt, B.J., and Thomas, K.L. 2004. Independent cellular processes for hippocampal memory consolidation and reconsolidation. Science 304: 839-843.

Lewis, D.J. 1979. Psychobiology of active and inactive memory. Psychol. Bull. 86: 1054-1083.

Lin, H.C., Mao, S.C., and Gean, P.W. 2006. Effects of intra-amygdala infusion of CB1 receptor agonists on the reconsolidation of fear-potentiated startle. Learn. Mem. 3: 316-321.

Mactutus, C.F., Riccio, D.C., and Ferek, J.M. 1979. Retrograde amnesia for old (reactivated) memory: Some anomalous characteristics. Science 204: 1319-1320.

Marsicano, G., Wotjak, C.T., Azad, S.C., Bisogno, T., Rammes, G. Cascio, M.G., Hermann, H., Tang, J., Hofmann, C., Zieglgansberger, W., et al. 2002. The endogenous cannabinoid system controls extinction of aversive memories. Nature 418: 530-534.

McGaugh, J.L. 2000. Memory-A century of consolidation. Science 287: 248-251.

Miller, C.A. and Marshall, J.F. 2005. Molecular substrates for retrieval and reconsolidation of cocaine-associated contextual memory. Neuron 47: 873-884.

Misanin, J.R., Miller, R.R., and Lewis, D.J. 1968. Retrograde amnesia produced by electroconvulsive shock after reactivation of a consolidated memory trace. Science 160: 554-555.

Myers, K.M. and Davis, M. 2002. Behavioral and neural analysis of extinction. Neuron 36: 567-584. 
Nader, K. 2003. Memory traces unbound. Trends Neurosci. 26: 65-72.

Nader, K., Schafe, G.E., and Le Doux, J.E. 2000. Fear memories require protein synthesis in the amygdala for reconsolidation after retrieval. Nature 406: 722-726.

Pavlov, I.P. 1927. Conditioned reflexes. Oxford University Press, London.

Paxinos, G. and Franklin, K.B.J. 1997. The mouse brain in stereotaxic coordinates. Elsevier Academic Press, San Diego.

Pedreira, M.E. and Maldonado, H. 2003. Protein synthesis subserves reconsolidation or extinction depending on reminder duration. Neuron 38: 863-869.

Przybyslawski, J. and Sara, S.J. 1997. Reconsolidation of memory after its reactivation. Behav. Brain Res. 84: 241-246.

Quirk, G.J., Garcia, R., and González-Lima, F. 2006. Prefrontal mechanisms in extinction of conditioned fear. Biol. Psychiatry 60: $337-343$

Rescorla, R.A. 2001. Experimental extinction. In Handbook of contemporary learning theories (eds. R.R. Mowrer and S. Klein), pp. 119-154. Lawrence Erlbaum Associates, Mahwah, NJ.

Rinaldi-Carmona, M., Barth, F., Heaulme, M., Shire, D., Calandra, B., Congy, C., Martinez, S., Maruani, J., Neliat, G., Caput, D., et al. 1994. SR141716A, a potent and selective antagonist of the brain cannabinoid receptor. FEBS Lett. 350: 240-244.

Rosenblum, K., Meiri, N., and Dudai, Y. 1993. Taste memory: The role of protein synthesis in gustatory cortex. Behav. Neural Biol. 59: $49-56$.

Sara, S.J. 2000. Retrieval and reconsolidation: Toward a neurobiology of remembering. Learn. Mem. 7: 73-84.
Schneider, A.M. and Sherman, W. 1968. Amnesia: A function of the temporal relation of footshock to electroconvulsive shock. Science 159: 219-221.

Suzuki, A., Josselyn, S.A., Frankland, P.W., Masushige, S., Silva, A.J., and Kida, S. 2004. Memory reconsolidation and extinction have distinct temporal and biochemical signatures. J. Neurosci. 24: 4787-4795.

Taubenfeld, S.M., Milekic, M.H., Monti, B., and Alberini, C.M. 2001. The consolidation of new but not reactivated memory requires hippocampal C/EBPß. Nat. Neurosci. 4: 813-818.

Tronel, S., Milekic, M.H., and Alberini, C.M. 2005. Linking new information to a reactivated memory requires consolidation and not reconsolidation mechanisms. PLoS Biol. 3: 1630-1638.

Tronson, N.C., Wiseman, S.L., Olausson, P., and Taylor, J.R. 2006. Bidirectional behavioral plasticity of memory reconsolidation depends on amygdalar protein kinase A. Nat. Neurosci. 9: 167-169.

Vianna, M.R., Szapiro, G., McGaugh, J.L., Medina, J.H., and Izquierdo, I. 2001. Retrieval of memory for fear-motivated training initiates extinction requiring protein synthesis in the rat hippocampus. Proc. Natl. Acad. Sci. 98: 12251-12254.

von Hertzen, L.S. and Giese, K.P. 2005. Memory reconsolidation engages only a subset of immediate-early genes induced during consolidation. J. Neurosci. 25: 1935-1942.

Received December 19, 2007; accepted in revised form March 31, 2008. 


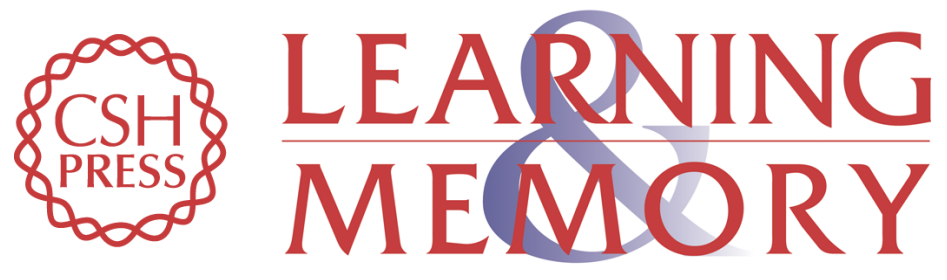

\section{Activation of LVGCCs and CB1 receptors required for destabilization of reactivated contextual fear memories}

Akinobu Suzuki, Takuya Mukawa, Akinori Tsukagoshi, et al.

Learn. Mem. 2008, 15:

Access the most recent version at doi:10.1101//m.888808

References This article cites 42 articles, 14 of which can be accessed free at:

http://learnmem.cshlp.org/content/15/6/426.full.html\#ref-list-1

License

Email Alerting Receive free email alerts when new articles cite this article - sign up in the box at the Service top right corner of the article or click here. 